Donald A. Barclay, Thomas Bustos, and Teal Smith

\title{
Signs of success
}

Digital signage in the library

$\mathbf{I}^{\mathrm{n}}$ n 2002, the University of California (UC)Merced, the tenth campus in the University of California system, was nothing more than empty fields and a few offices at a de-commissioned Air Force base. Given a clean slate on which to work, the librarians charged with creating a library for what would become a new research university for the 21st-century thought carefully about not only what they wanted to see in the new library, but also what they did not want to see. High on the not list was traditional library signage. While libraries have long used signage in attempts to inform li-

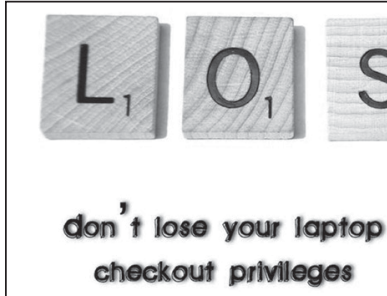
checkout privileges

solution is more chairs in Room B, not more signage in Room A); and

- a contributing factor to a library environment that feels unwelcoming, if not actually hostile.

To avoid going to down the path of a library overrun with ugly, ineffective, and unwelcoming signage, the UC-Merced Library planners zeroed in on digital signage. More than just a way to avoid the failings of traditional print-based signage, and certainly more than a piece of technological bling to adorn a shiny new building, we imagined digital signage as a way to open new doors for commu-

brary users as well as influence their behavior, the truth is that, more often than not, traditional library signage is:

- rendered ineffective through overuse;

- all but invisible to library users due to its static nature;

- produced on the cheap using substandard materials;

- allowed to become out of date, shop worn, or both;

- employed in futile attempts to solve underlying problems that signage cannot actually solve (e.g., if library users routinely move chairs from Room A to Room B, the
Donald A. Barclay is deputy university librarian, e-mail: dbarclay@ucmerced.edu, Thomas Bustos is library technology manager, e-mail: tbustos@ucmerced.edu, and Teal Smith is user communication and instruction librarian, e-mail: tsmith23@ucmerced.edu, at the University of California's-Merced Library,

๑ 2010 Donald A. Barclay, Thomas Bustos, and Teal Smith 
Getting from promising technology to essential component has been a long road. We hit some bumps and made some mistakes along the way, and we still have some distance to go before we can claim to be using digital signage to its fullest potential. However, the lessons learned by UC-Merced Library will help smooth the road for others who wish to employ digitalsignage technology in a library setting.

\section{What is digital signage?}

Digital signage is the display of information in electronic form, usually on a video display (LCD or plasma) or through a projector aimed at a screen or blank wall. Content can take the form of still images, animation, Web pages, or video. Digital signage may incorporate sound, screen crawls, or picture-in-a-picture technology as well as such interactive features as touch-screen functionality, two-way voiceand-video communication, and cellphone interaction.

In its simplest form, digital signage may consist of nothing more than a display device (a screen or projector) connected to a nonnetworked computer, the signage content of which is loaded manually via discs or flashmemory devices. While such simple solutions can work remarkably well in libraries where only one or two digital signs suffice, more complex hardware and software are required to manage multiple display devices.

Typically, complex digital signage systems include a networked server and commercially produced software that coordinate the flow of data to networked display devices, each of which has an on-board computer (a.k.a. "player" or "display engine") to process the data and push it to the display device in the form of images and audio. While display devices in complex systems are most often connected to a hardwired network, wireless interfaces are available to support display devices located in areas where hardwired network connections are not available.

\section{Choosing and implementing a digital signage system}

UC-Merced Library planners began the process of acquiring a digital signage system by developing a list of desired capabilities:

- display multiple still images with a high degree of control over order, frequency, length of display, and expiration date;

- operate across standard network infrastructure (CAT 6 cable);

- support a wide variety of standard file formats;

- provide a decentralized end-user interface that allows multiple frontline staff to act as content managers with the ability to create, post, and manage content;

- display video with the option to turn audio on or off at any display;

- display live Web pages;

- support (at least potentially) touchscreen functionality; and

- support (at least potentially) two-way, real-time voice-and-video interaction between a library user in front of a digital display and a library staff member at a service desk.

High hopes for digital signage soon enough ran into reality roadblocks. The initial digital signage system proved to be little more than 17 displays running what amounted to an unsophisticated electronic slide show.

Even with its disappointing limitations, the library's initial digital signage implementation was superior to traditional signage. Library staff created images that informed students and faculty about library information resources while showcasing library services, new books, librarian contact information, and more. Additionally, library digital signage displayed images of student-produced artwork, content provided by student groups, and information from such campus units as financial aid, student life, campus planning, international programs, career services, and tutoring. The variety, vibrancy, and currency of all this digital content far surpassed anything that could have been accomplished using print-based signage.

While the initial success was gratifying, it fell short of the original vision. Unwilling to accept the status quo, the library took the painful step of acquiring a new, more capable digital signage system. 


\section{Assessing success}

For library management, the most significant measure of the success of digital signage is that the library has not had to resort to traditional print-based signage in order to communicate with our community of library users.

The fact that campus departments, faculty, and student groups are eager to get their messages on the library's digital signage shows the medium is valued and seen as an effective means of communication by the entire UC-Merced campus community. From August 2008 through May 2010, the UC-Merced Library digital signage system displayed more than 300 unique signs, ${ }^{1}$ including several templates that are regularly updated

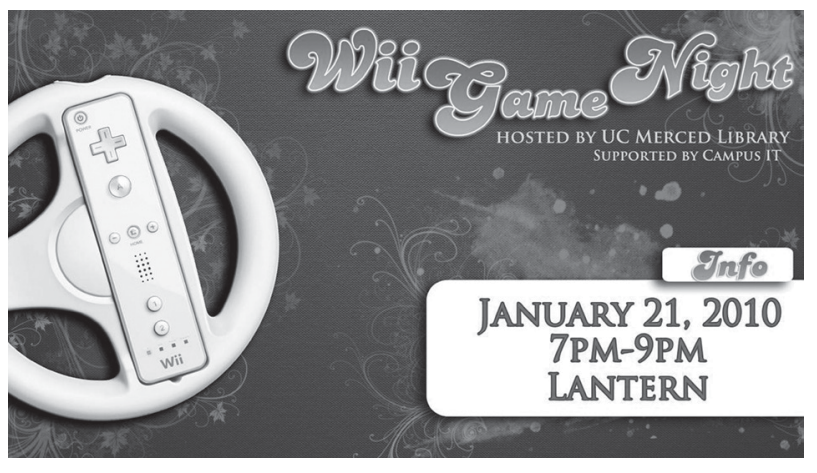

Digital sign from UC-Merced Library. Image by Jessica Julian. events, entertainment opportunities, club activities, profiles of fellow students-into a stream of more institutionally oriented messages only increases the likelihood that students will pay attention to digital signage. With outside content, however, comes a need for policies concerning what may or may not appear on digital signage.

For example, the display of commercial, political, and noncampus content are all areas where policy is needed. While no policy can (or should try to) anticipate every possible situation, beginning with a clear,
concise, and sensible digital signage policy will resolve most problems before they arise. In the case of student-generated content, UCMerced Library chose to avoid evaluating the appropriateness of such content, instead referring all student-generated content to the UC-Merced Office of Student Life, for evaluation, based on the same standards applied to the posting of printed matter on campus. For the sake of practicality, the library did established a policy regarding file sizes and formats to ensure that outside content can, in fact, be displayed on the digital signage system. All of the UC-Merced Library's digital signage policies are posted on the library Web site where potential content contributors can easily access them. ${ }^{2}$

\section{Unanticipated uses for digital signage}

Once digital signage was established in the library and recognized as a valuable resource by the campus community, several unanticipated uses emerged.

Though library planners never anticipated this, the library has often used digital signage to enhance and extend conventional static 
displays of art and artifacts. For example, in fall 2008, library digital signage displayed a video accompaniment to an undergraduatecurated display on the Holocaust.

Produced by one of the exhibit's undergraduate curators, this video history of the Holocaust ran for the entire three-month duration of the exhibit on a four-screen display cluster adjacent to the display cases containing the Holocaust-related artifacts that comprised the static portion of the exhibit. Because the Holocaust exhibit was both part of a course and an example of undergraduate research, the use of digital signage as part of the exhibit clearly illustrates its relevance to the teaching and research missions of both the university at large and the library in particular.

Digital signage has also played a surprise role on the development and public relations fronts. UC-Merced Library has used digital signage to recognize friends of the university and the library without the need to resort to walls covered with look-alike brass plaques that nobody reads. The library has also used the signs to publicize UC-Merced's outstanding record in the area of green building and environmental stewardship.

For First Lady Michelle Obama's appearance at UC-Merced's 2009 commencement, library staff created special digital signage to inform more than 12,000 campus visitors about the importance of academic libraries.

\section{Future enhancements}

The library has used audio on a few displays located far from areas where students normally study, but we would like to expand the use of audio without unduly disturbing studiers. Directional speakers offer a potential solution as they produce audio that can be heard within a prescribed area without bleeding out to areas where students are studying.

While the UC-Merced Library largely relies on screens to display digital signage, as these screens reach the end of their useful lives it is likely the library will replace them with short-throw projection systems. Most notably, short-throw projectors provide larger images at a much lower cost than screens. Because they can easily be mounted in the ceiling, short-throw projectors are less susceptible to theft or vandalism than wall-mounted screens. Short-throw projectors can be used in combination with products such as 3M's Vikuiti film to put eye-catching digital signage in spaces where screens cannot easily go, including directly on windows or high overhead in atriums. Yet another advantage of short-throw projection systems is that by simply turning off a projector, a digital sign can be temporarily "disappeared" if it is in the way of a special event or maintenance activity. Currently the UC-Merced Library is using one short-throw projector (set to cast a reversed image) to display digital signage on the frosted-glass front of the library's main service desk.

The UC-Merced Library has not used digital signage as an aid to wayfinding, but it is an area we wish to explore. One idea is to devote the display device in the first-floor elevator lobby to wayfinding. Another possibility is to install a touch-screen enabled wayfinding kiosk just inside the main entrance.

The ultimate digital signage goal for the UC-Merced Library is to provide increased interactivity through the use of touch-screen technology, cellphone interaction, and twoway real-time communication. When a digital display makes it possible for someone in a remote corner of the library or in another campus building to talk with and see a member of the library staff on the second floor, receive immediate one-on-one assistance, and even view what is on the staffer's desktop, then the word sign hardly conveys the depth of such a transaction.

\section{Conclusion}

While the UC-Merced Library has experienced its ups and downs with digital signage, the payoff has been tremendous. Digital signage has allowed the library to communicate with and engage our campus community far more effectively than we could have with printed signage. More importantly, the promise of

(continues on page 333) 
L. Clements Library in Ann Arbor, Michigan. This collection documents the political, educational, agricultural, and social activities of Norton Strange Townshend (181595), his wife (educator Margaret Bailey Townshend), and several generations of related families in northern Ohio and elsewhere. Townshend had a long and multifaceted career, which included antislavery activism, political involvement at the local level and in the U.S. House of Representatives, work on the Underground Railroad, a role as a medical inspector in the Civil War, and advocacy of scientific training for farmers. The latter earned him the nickname "the father of agricultural education in the United States" and allowed him to shape Ohio State University as a found and the institution's first professor of agriculture. In addition to primary sources such as correspondence, diaries, published and unpublished writings, ephemera and photographs, the collection contains 34 letters from Townshend's friend and mentor, Salmon P. Chase.
The E.H. Duckworth Photographic Ar-

chive, containing more than 5,000 photos documenting Nigerian life in the decades just before independence, has been acquired by Northwestern University Library's Melville J. Herskovits Library of African Studies. A British civil servant, Duckworth spent more than 20 years in Nigeria, where he was editor of and frequently a photographer for The Nigeria Magazine, which was founded to promote Nigerian national identity. His papers are now housed in the Bodleian Library of Commonwealth and African Studies at Rhodes House, Oxford, but the photographs-plus several hundred glass lantern slides and thousands of original negatives-have spent most of the past 40 years packed up in the travelling trunks in which Duckworth shipped them back to England. The archive complements other colonial African photo collections in the Herskovits Library-notably the Winterton Collection of East African Photographs-in that it records images intended for an African, rather than colonial, audience. $\boldsymbol{n}$

("Signs of success," continued from page 302)

what we will be able to do with digital signage in the future convinces us that we made the right choice when we turned our backs on traditional signage and made digital signage an integral part of our mission of teaching, research, and service.

\section{Notes}

1. For a video gallery of current and past signs, visit ucmercedlibrary.info/digitalsignage/digital-signage-gallery.html.

2. ucmercedlibrary.info/on-display /digital-signage.html. $n$
("And the winners are..." cont. from p. 321)

\section{University Libraries Section (ULS)}

Vice-chair/Chair-elect: Jan Kemp (379); Carol

G. Hixson (634).

Member-at-Large (3-year term): Michele M.

Reid (559); Rebecca Bernthal (461); Rachel Augello Erb (539).

\section{Western European Studies Section} (WESS)

Vice-chair/Chair-elect: James P. Niessen (55);

Gail P. Hueting (57).
Secretary: Karen Green (38); Jonathan C. Marner (60).

Member-at-Large (1-year term): Jeff Staiger (44); Heidi Madden (54).

\section{Women's Studies Section (WSS)}

Vice-chair/Chair-elect: Pamela Mann (64); Chimene Elise Tucker (47).

Secretary: Erin Gratz (24); Heather Lee Tompkins (89).

Member-at-Large (2-year term): Phyllis Hol-

man Weisbard (109); Write-in candidate (1). $n$ 